\title{
ResearchArticle
}

\section{Grain quality characteristics of two line hybrids in rice (Oryza sativa L.)}

\author{
V. KARPAGAM, R. VINOTH AND R. KALAIYARASI
}

\begin{abstract}
SUMMARY
Quality of rice is not always easy to define as it depends on the consumer and the intended and use for the grain. The best performing hybrids based on mean performance for grain yield, along with its parents were analyzed for physical and cooking quality characters. The hybrids viz., TNAU $27 \mathrm{~S} \times$ Improved white ponni, TNAU $27 \mathrm{~S} \times \mathrm{KDML} 105$, TS09 24× $\mathrm{CO}(\mathrm{R}) 49$, TS09 $24 \times$ BPT 5204, TS09 $26 \times$ ADT 38 had the highest values of hulling, milling and head rice recovery percentage. In the present study, the hybrids viz., TNAU 27S $\times$ KDML 105, TNAU 27S $\times$ BPT 5204 categorized under the long slender type and medium slender, respectively. Among the hybrids, TNAU 27S $\times$ KDML105 exhibited good milling out turn, head rice recovery, long slender, volume expansion, low gelatinization temperature, soft gel consistency with intermediate amylose content.
\end{abstract}

Key Words : Rice, Quality, Head rice recovery, Gel consistency, Amylose content

How to cite this article : Karpagam, V., Vinoth, R. and Kalaiyarasi, R. (2016). Grain quality characteristics of two line hybrids in rice (Oryza sativa L.). Internat. J. Plant Sci., 11 (2): 207-212, DOI: 10.15740/HAS/IJPS/11.2/207-212.

Article chronicle : Received : 25.02.2016; Revised : 11.04.2016; Accepted : 25.05.2016

\section{MEMBERS OF THE RESEARCH FORUM}

\section{Author to be contacted :}

V. KARPAGAM, Department of Plant Breeding and Genetics, Vanavarayar Institute of Agriculture, POLLACHI (T.N.) INDIA

Email: priyatnau2007@yahoo.co.in

Address of the Co-authors:

R. VINOTH AND R. KALAIYARASI, Centre for Plant Breeding and Genetics, Tamil Nadu Agricultural University, COIMBATORE (T.N.) INDIA 